\title{
The Albedo of Pervious Cement Concrete Linearly Decreases with Porosity
}

\author{
Rui Zhang, ${ }^{1}$ Guosheng Jiang, ${ }^{1}$ and Jia Liang ${ }^{2}$ \\ ${ }^{1}$ China University of Geosciences, 388 Lumo Road, Hongshan District, Wuhan 430074, China \\ ${ }^{2}$ College of Civil Engineering and Architecture, Guangxi University, 100 University Road, Nanning, Guangxi 530004, China \\ Correspondence should be addressed to Rui Zhang; rzhangcug@gmail.com
}

Received 13 January 2015; Revised 11 May 2015; Accepted 1 June 2015

Academic Editor: Dimitrios G. Aggelis

Copyright (c) 2015 Rui Zhang et al. This is an open access article distributed under the Creative Commons Attribution License, which permits unrestricted use, distribution, and reproduction in any medium, provided the original work is properly cited.

\begin{abstract}
Pervious pavements have been advocated as a potential countermeasure to the urban heat island effect. To understand if pervious pavements stay cooler than conventional pavements, the albedo of the pervious concrete must be understood. This study measured the albedo of pervious concrete with different porosity. Four Portland cement concrete mixes were casted, using designed amounts of sand to vary the porosity of the pervious concrete samples. The samples were sliced and the spectral reflectance and albedo of the sliced samples were measured and analyzed. It is found that the albedo of pervious concrete decreases linearly with the increase of the porosity. The albedo of a pervious Portland concrete varies from 0.25 to 0.35 , which is $0.05 \sim 0.15$ lower than the albedo of conventional cement concrete. Due to this lower albedo, it should be cautious to develop pervious concrete to battle with urban heat island unless the evaporation of pervious concrete is promoted to compensate the additional solar absorption caused by the low albedo.
\end{abstract}

\section{Introduction}

Pervious concrete is mixed by eliminated most or all fine aggregates from the mixture. Pervious pavements are used to allow storm water to percolate through their cavities and to recharge the groundwater. When percolating through a pervious pavement, some amount of water may be retained in the cavity. During the subsequent drying, the retained water evaporates, possibly decreasing the pavement temperature. Pervious concrete is thus advocated as a potential countermeasure to mitigate the urban heat island effect (UHI) [1-3].

However, to use the pervious pavements as an UHI mitigation effort, the designers must know if the thermal properties of pervious concrete are favorable to help the pervious pavements stay cooler than conventional pavements. Among these properties, the reflectivity, or the albedo, of pervious pavements, is the most important factor because the solar absorption is the product of the albedo and the solar irradiance, which is the driven force to the variation of the pavement temperature. While the porosity, evaporation, strength, and design of pervious concrete have been reported in many studies $[1,4-10]$, the solar reflectance of pervious concrete attains limited attention [11]. Furthermore, pervious concrete is prone to be clogged, which reduces the porosity of pervious concrete over time. It is thus necessary to characterize the albedo of pervious concrete and to estimate the albedo varying with the porosity.

This study measures the albedo of pervious concrete with a range of porosities. Four Portland cement concrete mixes are cast with designed amounts of sand to control the porosities. A spectrophotometer is used to measure the reflectances of samples. The albedo and the porosity are regressed, for a prediction of the albedo of pervious concrete.

\section{Experiments}

2.1. Sample Preparations. Four concrete mixes made with Portland cement, water, and coarse aggregates were produced. Ordinary type I Portland cement was selected for the experiments. The aggregate used was crushed limestone, with a single gradation from $0.5 \mathrm{~cm}$ to $1.0 \mathrm{~cm}$. It had an absorptivity of $0.55 \%$, observed density of $2725.7 \mathrm{~kg} / \mathrm{m}^{3}$, bulk density of $1452.1 \mathrm{~kg} / \mathrm{m}^{3}$, and a reflectivity of 0.42 (measured according to ASTM E903-12 [12]). By weight, a cement/aggregate ratio of 
1: 4 was used. To obtain differential porosity of the pervious concrete, the experiment used different amount of the fine sand to vary the porosity of the mixture. The ratio of the sand to the aggregate, in weight, was $0.1,0.2,0.3$, and 0.4 , respectively. The sand was in white-brown color, with a reflectivity about 0.45 (measured according to the ASTM E903-12 [12]). Details regarding the mixed components are tabulated in Table 1.

Selected mixtures were prepared by the use of a $0.05 \mathrm{~m}^{3}$ rotating-drum mixer. The aggregate was firstly casted in the mixer, and then the estimated absorbed water was spilled on the aggregate for $1 \mathrm{~min}$ mixture to ensure that the aggregate surface was wet. The cement was afterwards cast to the mixer for another $1 \mathrm{~min}$ mixture with the wet aggregate. Finally, the amount of the water needed for the desired water-to-cement ratio was added to the mixer for another 2 mins mixture. The concrete mixtures were cast in slender wood moulds with a dimension of $150 \times 150 \times 860 \mathrm{~mm}^{3}$. All mixtures were placed by lightly rodding 10 times in the three layers to ensure a uniform compaction in each lift. Mixtures in the mould were leveled by spatulas without any vibration compaction. They were moved to an air-conditioned, foggy room with $20^{\circ} \mathrm{C}$ and with more than $95 \%$ relative humidity for 3-day curing. After then, they were demolded and the pervious concrete blocks were restored in the air-conditioned room for another 25 days curing. Each cured block was drilled for six cores with a diameter of $100 \times 100 \mathrm{~mm}$. The cores were vacuum-washed to eliminate the drilling-left debris and then were submitted to porosity measurement. The porosity of pervious concrete $\phi$ was determined by

$$
\phi=1-\frac{\left(w_{2}-w_{1}\right)}{\rho_{s} V},
$$

where $w_{1}(\mathrm{~kg})$ is the sample weight under water, $w_{2}(\mathrm{~kg})$ is the oven-dry sample weight, $\rho_{s}\left(\mathrm{~kg} / \mathrm{m}^{3}\right)$ is the density of water at room temperature, and $V\left(\mathrm{~m}^{3}\right)$ is the volume of the sample. The sample was oven-dried at $105^{\circ} \mathrm{C}$ for 1.5 hours and subsequently left to cool in room temperature for measuring the oven-dry weight $w_{2}$. The sample's weight $w_{1}$ was measured by submerging and stirring the sample under water until the embedded air bubbles were completely evaluated from the sample. To obtain the volume of the cored sample, a Vernier Caliper was used to measure the length and diameter of each sample three times. The average was taken as the dimension of the sample.

2.2. Albedo Measurements. Some cored samples were sliced to round-plane samples with a thickness of $0.5-1.0 \mathrm{~cm}$, as shown in Figure 1(a). Three representative slices were selected for each mix, and a dense cement concrete slice sample was also used. The aggregate of the dense sample was limestone, but the water-to-cement ratio of the dense sample was unknown. After slicing, each sample was vacuum-cleaned and dried at room temperature for one day.

In total, 10 dry samples were subjected to spectral reflectance measurements. We used the Spectrophotometer Lambda 750 (Figure 1(a)) to measure the spectral reflectance of each sample six times and we selected three measurements with close spectral reflectance. The reflective spectrum, $R(\lambda)$, was a spectral curve showing the reflectivity to different wavelength $(\lambda=200 \mathrm{~nm} \sim 2.5 \mu \mathrm{m})$ of irradiance. The corresponding albedo, $\rho$, of a surface could be computed by

$$
\rho=\frac{\int_{\lambda_{0}}^{\lambda_{1}} R(\lambda) \times I(\lambda) d \lambda}{\int_{\lambda_{0}}^{\lambda_{1}} I(\lambda) d \lambda}
$$

where $\lambda_{0}=200 \mathrm{~nm}$ and $\lambda_{1}=2.5 \mu \mathrm{m} ; I(\lambda)$ is the spectrum of solar irradiance reaching the earth surface, which can be found at any textbook on the topic of solar radiation.

\section{Results}

Figure 2 shows the porosity of the samples with different sand ratios. For a specific sand ratio, three samples are tested. The measured porosity is different from the target porosity in Table 1. Even for samples with the same mixture, the measured porosity shows some deviations from the targeted porosity because of experimental errors. Despite the deviations, the average of the porosity of the sample decreases linearly with sand ratio.

Figure 3 shows the measured reflective spectrums of pervious concrete samples with different sand ratios and of the dense sample. The dense concrete sample has spectral reflectance of $0.35-0.40$, which is the typical reflectivity of Portland concrete $[13,14]$. Reducing the fine aggregate (sand) increases the porosity of the samples and thus decreases the albedo of the samples. The same trend has been observed by [11], which found pervious concrete pavement with a solar reflectance index (SRI) of 14 and traditional concrete pavement with a SRI of 37 . The reason may be that the diffuse radiation from a rough surface may return to the surface, increasing the absorption and decreasing the reflectivity [15]. The photons entering the cavity are subjected to multiple deflections, each of which attenuates the radiation and decreases the reflection.

The reflectance of ultraviolet and visual lights decreases more than the reflectance of infrared light. The reason for this difference may be that the cavities at the surface of the sample are absorptive to the ultraviolet and visual lights, which have short wavelength. The cavity at a pervious concrete surface can be analogized as a black hole. Once ultraviolet and visual lights arrive in the cavities, they tend to be absorbed, without an effective reflectance like aggregate surface and cement matrix. In comparison, infrared light can be less absorptive to the cavity because infrared light has longer wavelength than ultraviolet and visual light. Adding sand reduces the cavity, and the radiation reaching the sand tends to be reflected proportionally to the reflectivity of the sand.

Pavement engineers are more interested in the albedo of a pavement surface. Figure 4 plots the albedo of the pervious concrete samples. The dense sample has a porosity of 0.07 and an albedo of about 0.39 , representing the typical albedo of the normal concrete [13]. The albedo decreases linearly with the increase of the porosity. The slope of decreasing is 0.51 , meaning that an increase of 0.10 porosity would reduce the albedo by 0.05 . Pervious concrete has a porosity 
TABLE 1: Mix proportion.

\begin{tabular}{lccccccccc}
\hline Number & Sand ratio $S$ & w/c ratio & \multicolumn{3}{c}{ Mix $\left(\mathrm{kg} / \mathrm{m}^{3}\right)$} & \multicolumn{3}{c}{$\begin{array}{c}\text { Target } \\
\text { porosity }\end{array}$} & $\begin{array}{c}\text { Density } \\
\left(\mathrm{kg} / \mathrm{m}^{3}\right)\end{array}$ \\
\hline 1 & 0.10 & 0.28 & 243.03 & 1518.92 & 151.89 & 2.43 & 124.20 & 0.35 & 1701 \\
2 & 0.20 & 0.28 & 245.89 & 1536.79 & 307.36 & 2.46 & 125.66 & 0.30 \\
3 & 0.30 & 0.28 & 248.81 & 1555.07 & 466.52 & 2.49 & 127.16 & 0.25 & 1737 \\
4 & 0.40 & 0.28 & 251.81 & 1573.80 & 629.52 & 2.52 & 128.69 & 0.20 & 1928 \\
\hline
\end{tabular}

${ }^{*}$ The density was tested after the samples were fully cured.

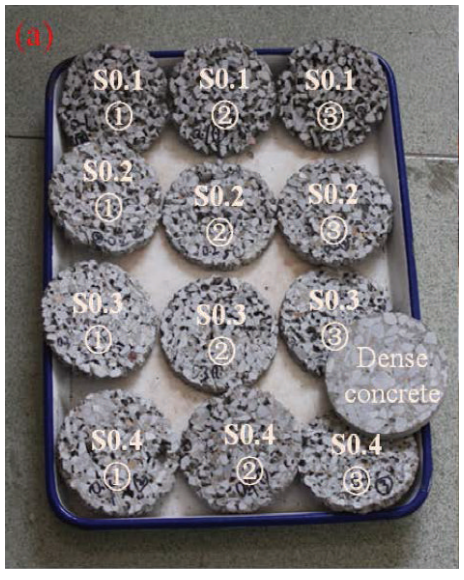

(a)

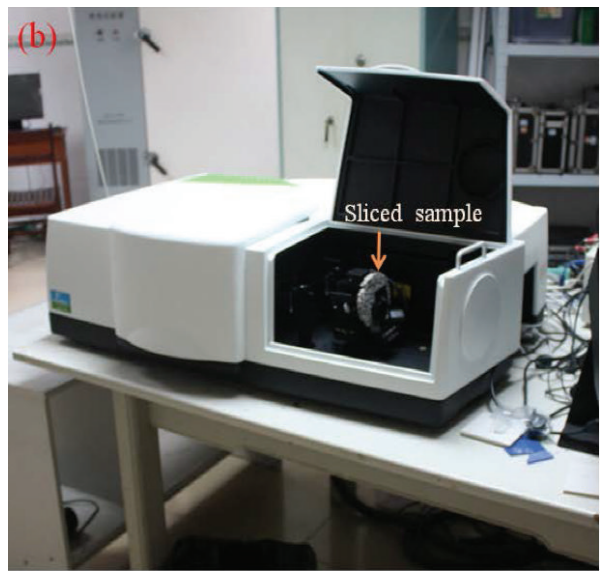

(b)

FIGURE 1: Sliced samples prepared for spectral reflectance test. (a) Pervious concrete slices. (b) Spectrophotometer Lambda 750.

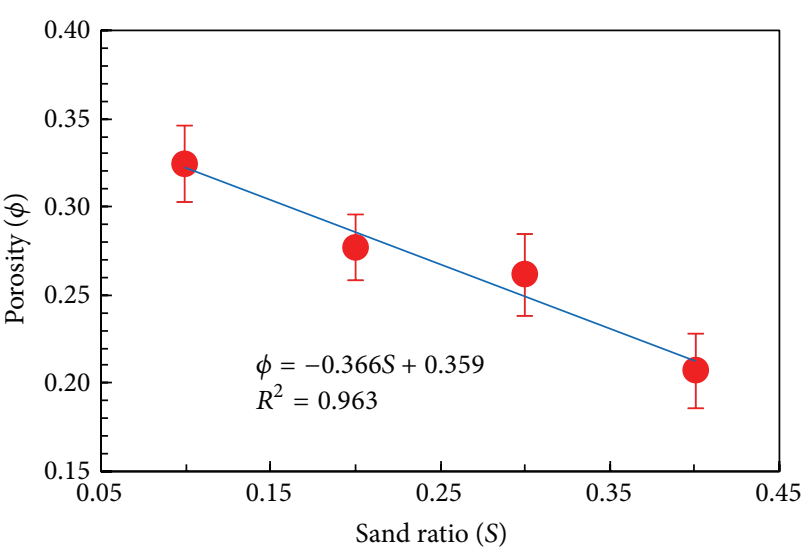

FIGURE 2: Porosity and sand ratio.

about $0.15 \sim 0.30$, which is $0.10 \sim 0.25$ greater than the porosity of conventional dense concrete. Accordingly, the albedo of porous concrete is about $0.05-0.15$ lower than the albedo of dense concrete.

\section{Discussion}

Pervious concrete has been advocated as a potential countermeasure to mitigate the urban heat island because pervious concrete can hold rainwater in internal pores for evaporative

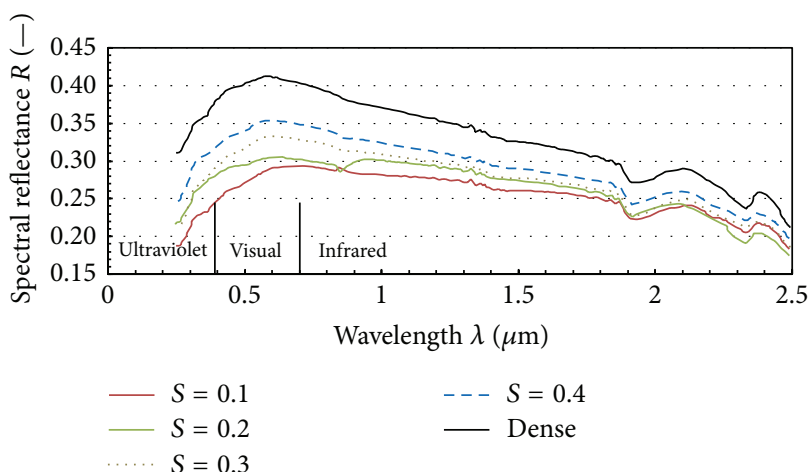

FIGURE 3: Spectral reflectance, $R$ (-), of the pervious concrete with different sand ratio.

cooling during the dry, hot summer day. However, measurements in field and in lab have shown that the evaporation of the pervious concrete contributed very limitedly to the evaporative cooling of pervious pavements, especially days after wetting $[4,16]$. Pervious concrete has higher surface temperature than normal concrete during daytime but lower temperature during nighttime $[17,18]$. Pervious hot-mix asphalt pavements have the highest predicted daytime surface temperatures and lowest nighttime temperatures [19], in comparison to pervious cement concrete and dense concrete.

The reason for this hot surface temperature observed at pervious pavements is because pervious concrete has 


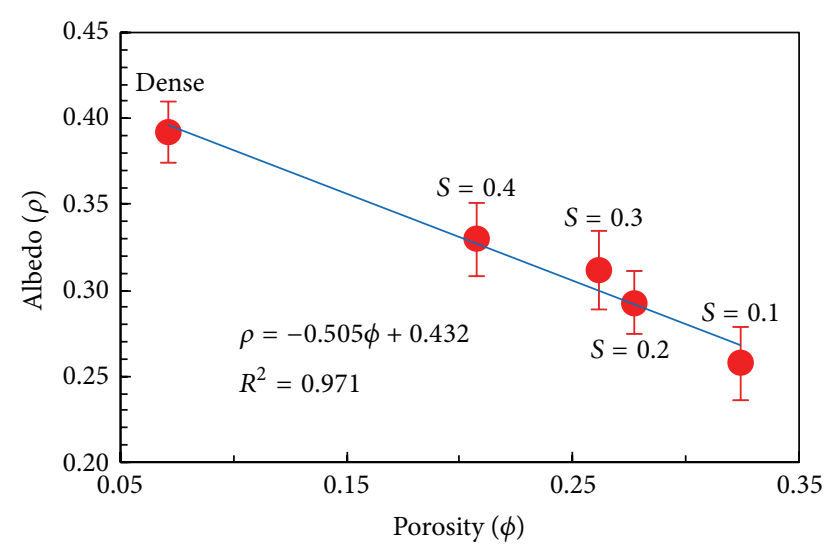

FIgURE 4: The albedo of pervious concrete with different porosity.

lower reflectivity and tends to absorb more solar radiation. According to the slope in Figure 4, the albedo of pervious concrete is about $0.05 \sim 0.15$ lower than that of dense concrete. Considering a typical summer day with a zenith solar radiation of $1000 \mathrm{~W} / \mathrm{m}^{2}$, the pervious concrete can absorb 50 $150 \mathrm{~W} / \mathrm{m}^{2}$ additional solar radiation. At midday in summer, the evaporation of the dry pervious concrete contributes about $33-47 \mathrm{~W} / \mathrm{m}^{2}$ or even lower to the heat loss of the pervious surface $[3,16,20]$. Therefore, pervious pavements tend to absorb additional heat compared to dense pavements. This heat gained will heat up the pervious concrete surface because this concrete has lower heat volumetric capacity and lower thermal conductivity than dense concrete. Pervious pavements thus stay hotter than dense pavements unless the heat gained at the surface due to the low albedo is compensated by the evaporation. Therefore, it is cautious to develop pervious concrete to mitigate the urban heat island.

Increasing the albedo of pervious concrete may be practically important to mitigate urban heat island on the dimension of pavement engineering. As the reflectivity of aggregates, binders, and voids contributes simultaneously to the reflectivity of pervious concrete, increasing the aggregate and the binder albedo may be the right engineered solution to increase the albedo because the cavity needs to be kept at a desirable level to drain the rainwater. Further experiments are expected to measure the albedo of pervious concrete with light-colored aggregates and colored cement in the mixture.

\section{Conclusions}

Pervious Portland concrete has an albedo of about 0.25 0.35 at density of $\sim 1700 \sim 1950 \mathrm{~kg} / \mathrm{m}^{3}$, which is about $0.05-$ 0.15 lower than the albedo of the dense Portland concrete. Pervious concrete albedo linearly decreases with the increase of porosity because the cavities at the porous concrete surface are absorptive. This low albedo results in an additional solar absorption of $50-150 \mathrm{~W} / \mathrm{m}$ during the midday in summer. Therefore, it is cautious to develop pervious concrete to mitigate the urban heat island. Further experiments are expected to measure the albedo of pervious concrete with highreflectivity aggregates and colored cement in the mixture.

\section{Conflict of Interests}

The authors declare that there is no conflict of interests regarding the publication of this paper.

\section{Acknowledgment}

The authors thank Professor Jiang He at Guangxi University, China, for the use of Spectrophotometer Lambda 750.

\section{References}

[1] M. Kayhanian, D. Anderson, J. T. Harvey, D. Jones, and B. Muhunthan, "Permeability measurement and scan imaging to assess clogging of pervious concrete pavements in parking lots," Journal of Environmental Management, vol. 95, no. 1, pp. 114-123, 2012.

[2] Y. Qin and J. E. Hiller, "Understanding pavement-surface energy balance and its implications on cool pavement development," Energy and Buildings, vol. 85, pp. 389-399, 2014.

[3] H. Li, J. T. Harvey, T. J. Holland, and M. Kayhanian, "The use of reflective and permeable pavements as a potential practice for heat island mitigation and stormwater management," Environmental Research Letters, vol. 8, no. 1, Article ID 015023, 2013.

[4] C. Syrrakou and G. F. Pinder, "Experimentally determined evaporation rates in pervious concrete systems," Journal of Irrigation and Drainage Engineering, vol. 140, no. 1, Article ID 04013003, 2014.

[5] J. T. Kevern, L. Haselbach, and V. R. Schaefer, "Hot weather comparative heat balances in pervious concrete and imprevious concrete pavement systems," Journal of Heat Island Institute International, vol. 7, no. 2, pp. 231-237, 2012.

[6] J. Li, "Mix design of pervious recycled concrete," in Performance Modeling and Evaluation of Pavement Systems and Materials, pp. 103-108, 2011.

[7] J. P. Coughlin, C. D. Campbell, and D. C. Mays, "Infiltration and Clogging by sand and clay in a pervious concrete pavement system," Journal of Hydrologic Engineering, vol. 17, no. 1, pp. 6873, 2011.

[8] A. P. Galvín, J. Ayuso, F. Agrela, A. Barbudo, and J. R. Jiménez, "Analysis of leaching procedures for environmental risk assessment of recycled aggregate use in unpaved roads," Construction and Building Materials, vol. 40, pp. 1207-1214, 2013.

[9] Y. Qin, H. Yang, Z. Deng, and J. Zhang, "A simplified model for computing pollutants release from granular pavement base to local aquifer," Environmental Earth Sciences, vol. 72, no. 5, pp. 1533-1540, 2014.

[10] Y. Qin, H. Yang, Z. Deng, and J. He, "Water permeability of pervious concrete is dependent on the applied pressure and testing methods," Advances in Materials Science and Engineering, vol. 2015, Article ID 404136, 6 pages, 2015.

[11] L. Haselbach, M. Boyer, J. T. Kevern, and V. R. Schaefer, "Cyclic heat island impacts on traditional versus pervious concrete pavement systems," Transportation Research Record: Journal of the Transportation Research Board, no. 2240, pp. 107-115, 2011.

[12] ASTM-E903-12, Standard Test Method for Solar Absorptance, Reflectance, and Transmittance of Materials Using Integrating Spheres, ASTM International, West Conshohocken, Pa, USA, 2012.

[13] R. Levinson and H. Akbari, "Effects of composition and exposure on the solar reflectance of portland cement concrete," 
Cement and Concrete Research, vol. 32, no. 11, pp. 1679-1698, 2002.

[14] Y. Qin, "Urban canyon albedo and its implication on the use of reflective cool pavements," Energy and Buildings, vol. 96, pp. 86-94, 2015.

[15] P. Berdahl, H. Akbari, J. Jacobs, and F. Klink, "Surface roughness effects on the solar reflectance of cool asphalt shingles," Solar Energy Materials and Solar Cells, vol. 92, no. 4, pp. 482-489, 2008.

[16] E. M. Nemirovsky, A. L. Welker, and R. Lee, "Quantifying evaporation from pervious concrete systems: methodology and hydrologic perspective," Journal of Irrigation and Drainage Engineering, vol. 139, no. 4, pp. 271-277, 2013.

[17] J. T. Kevern, L. Haselbach, and V. R. Schaefer, "Hot weather comparative heat balances in pervious concrete and impervious concrete pavement systems," in Proceedings of the 2nd Annual Conference on Countermeasures to Urban Heat Islands, pp. 1-9, Berkeley, Calif, USA, 2009.

[18] J. T. Kevern, V. R. Schaefer, and K. Wang, "Temperature behavior of pervious concrete systems," Transportation Research Record, vol. 2098, no. 1, pp. 94-101, 2009.

[19] J. Stempihar, "Porous asphalt pavement temperature effects for urban heat island analysis," Transportation Research Record: Journal of the Transportation Research Board, no. 2293, pp. 123130, 2012.

[20] M. Aida and K. Gotoh, "Urban albedo as a function of the urban structure-a two-dimensional numerical simulation," Boundary-Layer Meteorology, vol. 23, no. 4, pp. 415-424, 1982. 

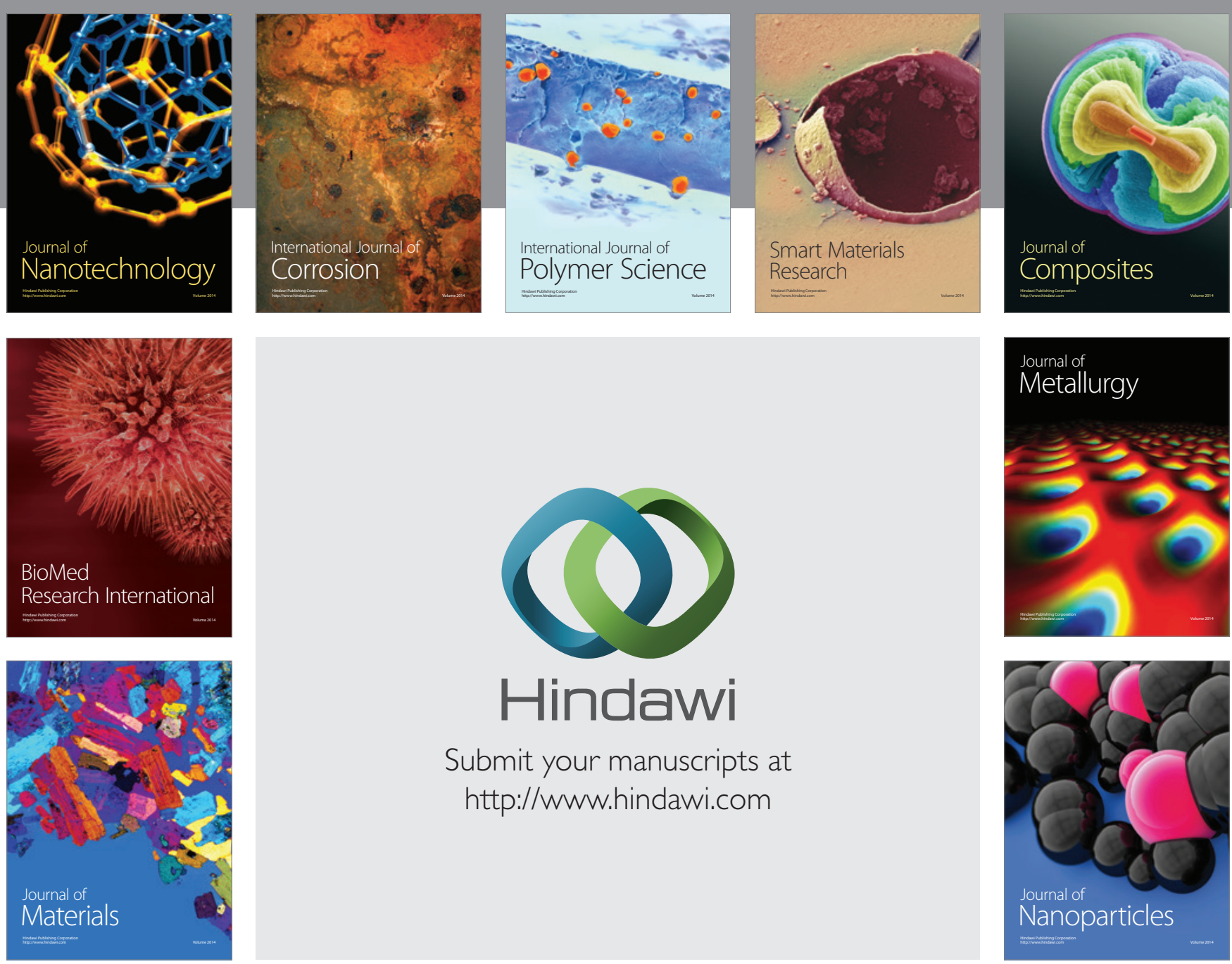

Submit your manuscripts at http://www.hindawi.com
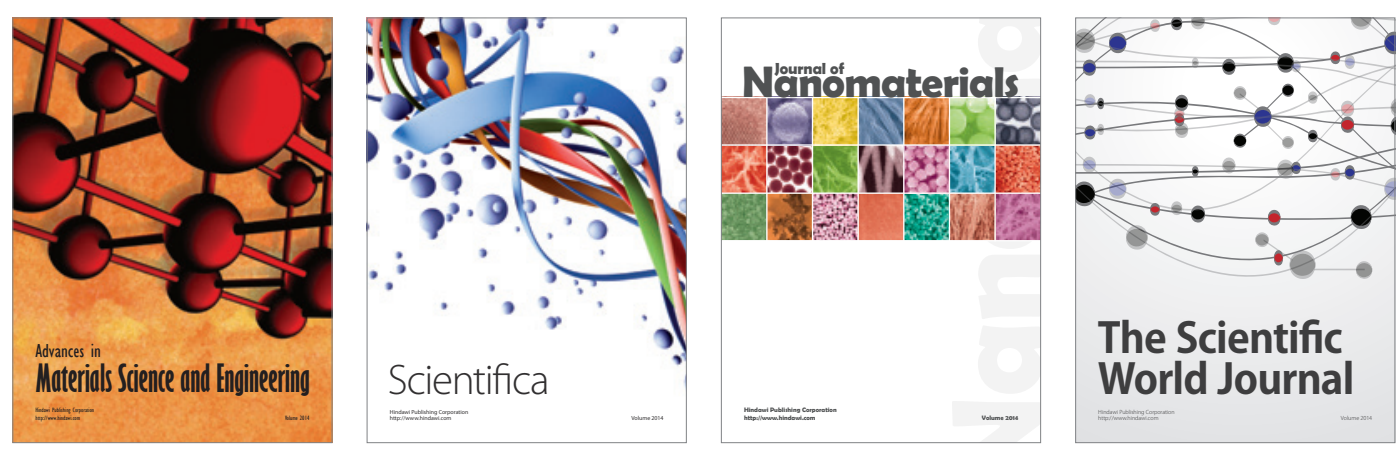

\section{The Scientific World Journal}
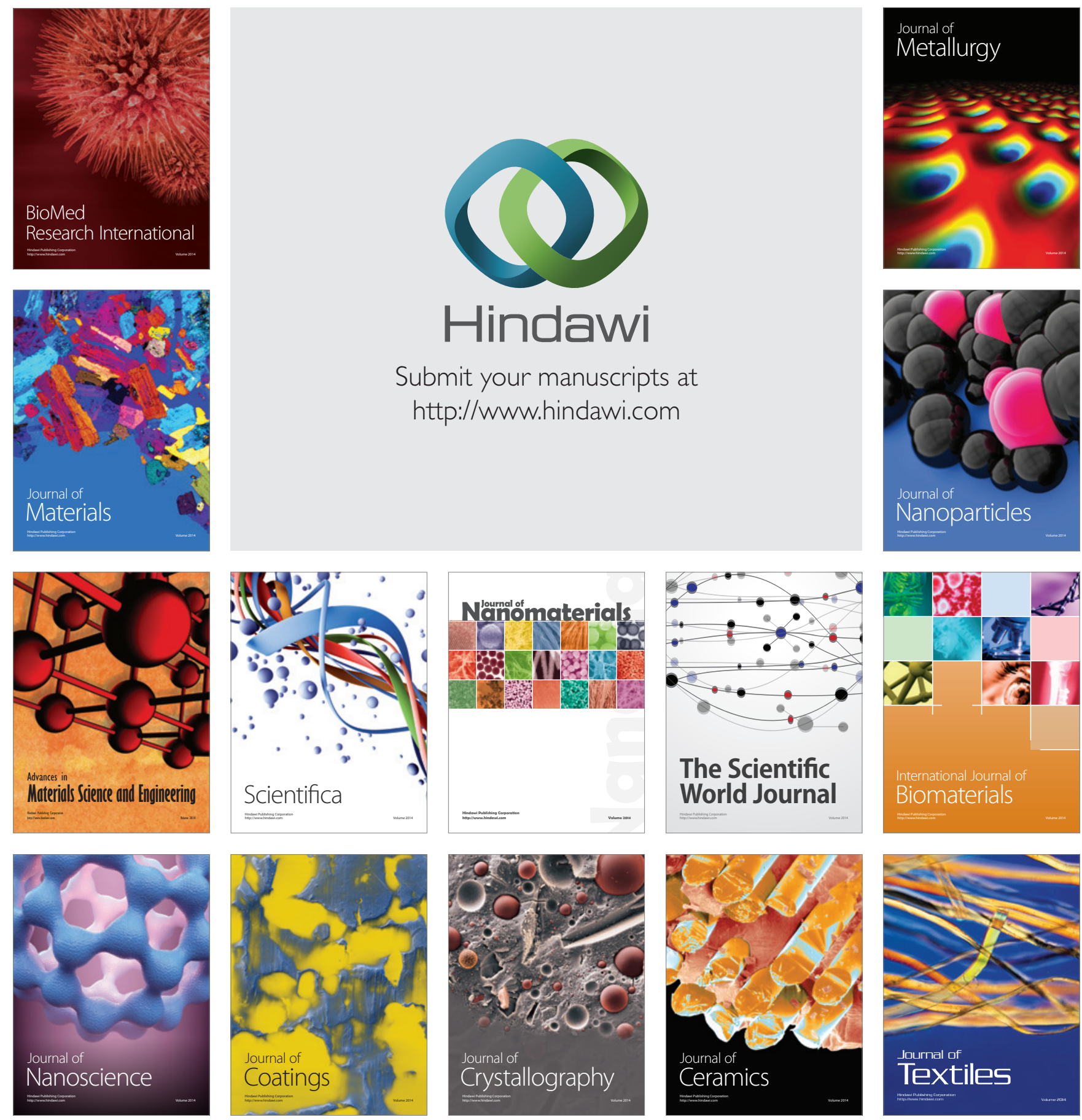